\begin{tabular}{llll}
\hline \multirow{3}{*}{$\begin{array}{ll}\text { Avinash Aujayeb, } \\
\text { Ann Ward }\end{array}$} & Cardiothoracic Dept, & A. Aujayeb, Cardiothoracic & a aujayeb@doctors.net.uk \\
& Freeman Hospital, & Dept, Freeman Hospital, & \\
& Newcastle Upon Tyne & Newcastle Upon Tyne & \\
& Hospitals NHS Trust, & Hospitals NHS Trust, \\
& Newcastle, UK & Newcastle, NE7 7DN, UK
\end{tabular}

\title{
A surgical case of haemothorax
}

\section{Case Report}

An 83-year-old female presented with a 6-day history of painless jaundice, anorexia, dark urine, steatorrhea and weight loss of $10 \mathrm{~kg}$ over the past year. The only past medical history was a monoclonal gammopathy of unknown significance. She was a neversmoker and did not drink alcohol.

On examination, she was apyrexial and normotensive. She was clinically jaundiced, and had $4 \mathrm{~cm}$ non-tender hepatomegaly.

Initial blood tests revealed a bilirubin concentration of $166 \mu \mathrm{mol} \cdot \mathrm{L}^{-1}$ (normal range o-21 $\left.\mu \mathrm{mol} \cdot \mathrm{L}^{-1}\right)$, alkaline phosphatase of 371 units $\cdot \mathrm{L}^{-1}$ (normal range 30-150 units $\mathrm{L}^{-1}$ ) and an alanine transaminase of 145 units $\mathrm{L}^{-1}$ (normal range $0-40$ units $\cdot \mathrm{L}^{-1}$ ). Her renal function and inflammatory markers were normal. An abdominal ultrasound showed intra-hepatic biliary dilatation, suggesting obstruction in the lower common bile duct. She went on to have a computed tomography (CT) scan of her abdomen, which showed a small amount of ascites, peritoneal nodularity, bile duct dilatation and a mass in the body and tail of the pancreas involving the aorta and left adrenal gland.

Several attempts at a percutaneous transhepatic cholangiogram (PTC) were made, but the radiologist was unable to cannulate the biliary ducts. A stent was then inserted at endoscopic retrograde cholangiopancreatography (ERCP) and a biopsy of the mass was carried out.
$24 \mathrm{~h}$ later the patient deteriorated with pyrexias, hypotension and new onset atrial fibrillation with a fast ventricular rate. Her white blood cell count rose to $16.5 \times 10^{9}$ cells $\cdot \mathrm{L}^{-1}$ from $12.4 \times 10^{9}$ cells $\cdot \mathrm{L}^{-1}$ and her C-reactive protein to $52 \mathrm{mg} \cdot \mathrm{L}^{-1}$ (normal level less than $5 \mathrm{mg} \cdot \mathrm{L}^{-1}$ ). Her haemoglobin dropped from $116 \mathrm{~g} \cdot \mathrm{L}^{-1}$ to $93 \mathrm{~g} \cdot \mathrm{L}^{-1}$. Her kidney and liver function tests also deteriorated and a chest radiograph showed a new right pleural effusion (fig. 1). It was noted that on the CT scan carried out a few days earlier no pleural disease was observed.

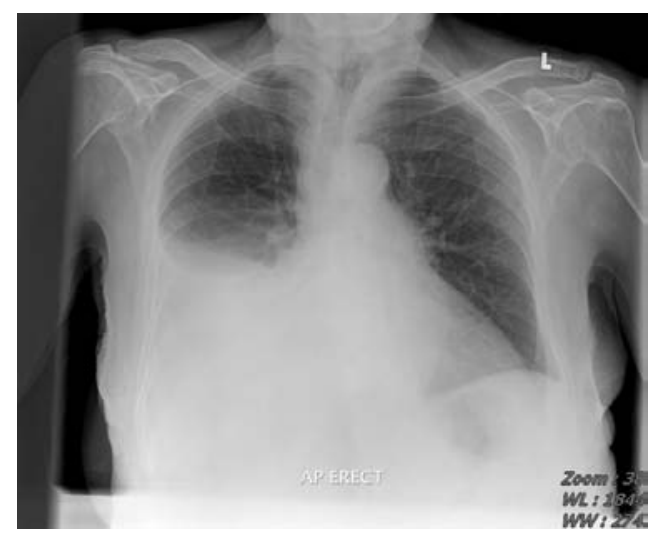

Figure 1

Chest radiograph showing right pleural effusion.
Statement of Interest None declared. 

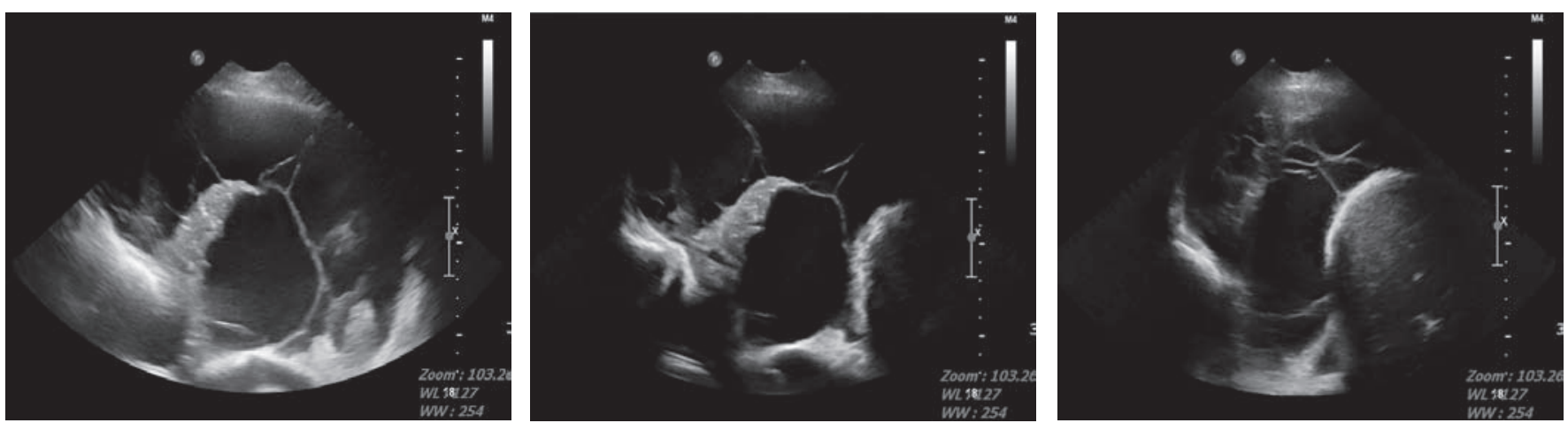

Figure 2

Thoracic ultrasound.

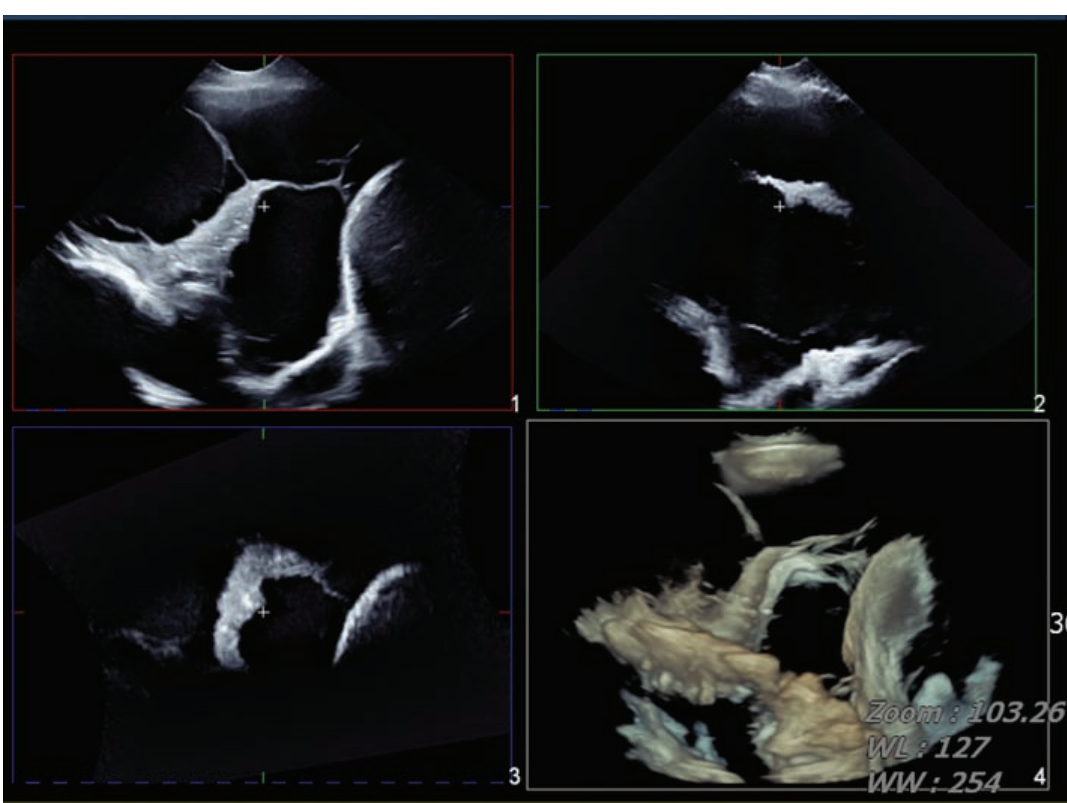

Figure 3

Thoracic ultrasound. was then transferred to the respiratory ward and a departmental thoracic ultrasound was requested (figs 2-3).

The biopsy from the ERCP showed a cholangiocarcinoma.
She was treated with beta-blockers, intravenous piperacillin sodium/tazobactam sodium and intravenous fluids. A respiratory consult was sought.

It was noted that on admission she had an arterial oxygen saturation of $95 \%$ on air, and that at the time of referral, she was saturating at $95 \%$ on $4 \mathrm{~L}$ supplemental oxygen via nasal cannulae. She had a respiratory rate of 26 breaths $\mathrm{min}^{-1}$, was normotensive and had an irregular pulse of 80 beats $\cdot \min ^{-1}$. Her platelet count and prothrombin time were normal and a pleural tap was attempted at the bedside under ultrasound guidance. Two attempts at pleural aspiration yielded blood, and only $10 \mathrm{~mL}$ could be aspirated each time. The patient

\section{Task 1}

What is the likely cause of the pleural effusion at this moment in time?

a. Metastatic disease

b. Pneumonia

c. Tracking of ascites from the abdomen

d. Inadequate pump action from the heart due to atrial fibrillation and sepsis

e. Interventional complication from ERCP and PTC 


\section{Answer 1}

e. Interventional complication from ERCP and PTC

PTC is a safe and effective technique to determine and treat biliary blockage [1]. Under asepsis, a small gauge needle is placed into the biliary tree under ultrasound guidance and contrast is then injected. A stent is then placed for either internal or external drainage. The risks of the procedure (sepsis, cholangitis, bile leak, haemorrhage and pneumothorax) are each quoted as $2 \%$ [1].

\section{Task 2}

What is the most accurate description of the ultrasound appearances?

a. A simple anechoic pleural effusion

b. A simple echogenic pleural effusion

c. A heavily septated and loculated effusion with no collapsed lung

d. A heavily septated and loculated effusion with atelectatic lung demonstrated by a tongue-like structure floating in the fluid

e. Normal lung appearances with comet tail signs 


\section{Answer 2}

d. A heavily septated and loculated effusion with atelectatic lung demonstrated by a tongue-like structure floating in the fluid
Ultrasound is reliable and efficient in identifying pleural effusions along with other pleural diseases. It is cost-effective, involves no radiation and can be carried out at the bedside. It is currently a training requirement in the UK that all respiratory trainees should be competent in the use of thoracic ultrasound [2]. This involves being observed by a suitably qualified ultrasound practitioner performing 20 thoracic ultrasound scans on normal patients, 10 ultrasound scans on pleural effusions and five drain placements or thoracocentesis. As such, by continuing this practice, one can develop a safe level of proficiency.

Pleural fluid appears as an echo free image. Ultrasound employs high frequency sound waves and the echoes are reflected back by body components. If the ultrasound wave is transmitted it produces an echo-free area on the image.

Pleural fluid can be described according to appearances seen $[3,4]$. Atelectatic lung can often be seen and has been described as a tongue-like structure or having an inverted hockey stick appearance. Effusions can be classified as anechoic (echo-free spaces in fluid), echogenic (no echo-free spaces), complex non-septated (echogenic material as well as anechoic fluid with floating fibrin strands) and complex septated. Transudates are usually anechoic. Exudates may be echogenic.

Pleural fluid analysis revealed a $\mathrm{pH}$ of 7.16, lactate dehydrogenase (LDH) of 1622 units $L^{-1}$ (plasma LDH not carried out), fluid protein of $42 \mathrm{~g} \cdot \mathrm{L}^{-1}$ (plasma protein $62 \mathrm{~g} \cdot \mathrm{L}^{-1}$ ) and fluid glucose of $2.3 \mathrm{mmol} \cdot \mathrm{L}^{-1}$ (plasma glucose $6.2 \mathrm{mmol} \cdot \mathrm{L}^{-1}$ ). Gram stain was negative and no organisms were seen.

Pleural cytology was requested but the samples were lost in the department.

\section{Task 3}

What diagnosis is suggested by the pleural fluid appearance, analysis and the imaging provided?
a. An empyema
b. A transudative effusion caused by ineffective cardiac pump action
c. A malignant pleural effusion
d. A haemothorax
e. A chylothorax 


\section{Answer 3}

\section{d. A haemothorax}

The application of Light's criteria (pleural fluid protein divided by serum protein $>0.5$ ) [5] and the very high pleural fluid LDH shows that the aspirate is an exudate. The bloody pleural fluid, the ultrasound appearances and the knowledge of how a PTC was performed all made it highly likely that this was a haemothorax caused by failed attempts at PTC.

\section{Task 4 \\ What was the therapeutic option we opted for? \\ a. A small bore (12 French Seldinger) chest drain with bedside ultrasound \\ b. A small bore (12 French Seldinger) chest drain with ultrasound done in radiology department \\ c. A large bore (24 or 38 French) Seldinger chest drain \\ d. Video assisted thoracoscopy to drain pleural effusion \\ e. Supportive care}

\section{Answer 4}

b. A small bore (12 French Seldinger) chest drain with ultrasound done in radiology

department

The patient was dyspnoeic and hypoxic. 2 units of blood were transfused. A chest drain was required, but only $10 \mathrm{~mL}$ of fluid had been aspirated on pleural taps. The effusion was septated and loculated and we felt that a consultant radiologist should attempt a drain in the biggest locule seen on a departmental, rather than a portable, ultrasound machine. Upon review of the images, the radiologist felt that whilst there were loculations, all the pockets of fluid were communicating with each other and that a small bore (12 French Seldinger) would be effective.

A chest drain was inserted with no complications and $3 \mathrm{~L}$ of blood was readily drained. Serial chest radiography showed resolution of the pleural effusion (fig. 4). The patient's arterial oxygen saturation improved to $94 \%$ on air and her dyspnoea resolved. She was eventually discharged with oncological follow-up.
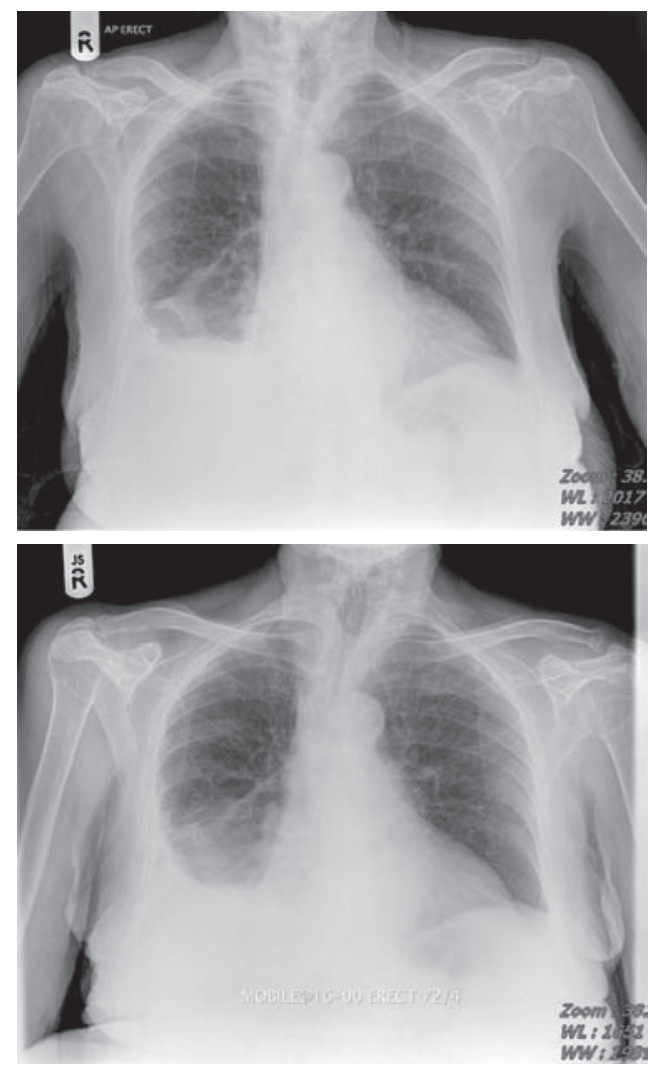

Figure 4

Chest radiography. 


\section{Conclusions}

From a respiratory perspective, the outcome for the patient was satisfactory. This case highlights the fact that a good knowledge of interventional procedures is vital for physicians, especially if they are working in a tertiary referral centre such as ours.

Through this case, we have an intimate knowledge of how a PTC is performed and that structures such as the diaphragm and pleura can be injured.

Level 1 competency at thoracic ultrasound enables respiratory physicians to perform pleural procedures safely at the bedside in uncomplicated cases and reduces the workload of the ultrasound department. It is important to refer more complex cases for the opinion of a more experienced ultrasound practitioner.

\section{Summary}

An 83-year-old patient presented with obstructive derangement of her liver function tests and was diagnosed with metastatic cholangiocarcinoma. Several attempts at drainage via PTC were made and she developed biliary sepsis, newonset atrial fibrillation and a right pleural effusion. This was septated and loculated on ultrasonography. $3 \mathrm{~L}$ of bloody fluid drained with a Seldinger chest tube. The haemothorax was thought to be due to the failed PTCs. The patient recovered to be discharged home and followed up by oncology.

\section{References}

1. Saad WE, Wallace MJ, Wojak JC, et al. Quality improvement guidelines for percutaneous transhepatic cholangiography, biliary drainage, and percutaneous cholecystostomy. J Vasc Interv Radiol 2010; 21: 789-795.

2. The Royal College of Radiologists. Ultrasound Training Recommendations for Medical and Surgical Specialties. 2nd Edn. www.rcr.ac.uk/docs/radiology/ pdf/BFCR(12)17_ultrasound_training.pdf Date last accessed: July 102013.
3. Koh DM, Burke S, Davies N, et al. Transthoracic US of the chest: clinical uses and applications. Radiographics 2002; 22: el.

4. Tsai TH, Yang PC. Ultrasound in the diagnosis and management of pleural disease. Curr Opin Pulm Med 2003; 9: 282-290.

5. Light RW, MacGregor MI, Luchsinger PC, et al. Pleural effusions: the diagnostic separation of transudates and exudates. Ann Intern Med 1972; 77: 507-513. 